\title{
RESEARCH OF ELECTRODES ENABLING THE PRODUCTION OF NANOFIBRES WITH DEFINED FINENESS
}

\author{
Josef SKŘIVÁNEK, Jiří KOMÁREK, Ondřej BAŤKA \\ TUL - Technical University of Liberec, Department of Textile Machine Design, Liberec, Czech Republic, EU, \\ Josef.skrivanek@tul.cz
}

https://doi.org/10.37904/nanocon.2020.3730

\begin{abstract}
The main scope of work is to verify the possibility of production diverse fibres, which have different fineness and are produced simultaneously on one electrode. In the first phase of the research, a basic design of the geometry of the two-stage electrode was performed and subsequently, using FEM software, an analysis was performed to determine the electrical field at the individual stages of the electrode. Based on the distribution of the electrical field, 3 different types of the two-stage electrode geometry were found, the mutual structure of stages on one electrode. In the second phase, these 3 types were created and then an experiment was performed and a subsequent evaluation of the frequency and fineness of the fibres related to the solved types of electrodes.
\end{abstract}

Keywords: Fineness, electrical field, spinning electrode, electrospinning

\section{INTRODUCTION}

Nanomaterials are currently a very interesting and not yet fully explored field of scientific activity. There are specific materials that have at least one dimension smaller than $10 \mathrm{~nm}$. Most often, these materials have the shape of a cylinder, tube or sphere in cross sections. Cylindrical nanomaterials are called nanofibers. "The principle of nanofiber production is their elongation and thinning with the help of external forces [1].

Forms of nanofiber products are diverse. Commonly known are flat nanofiber fabrics, which are usually applied to a backing material in the form of a nonwoven fabric. Another very important product from the portfolio of nanofibers is bi-component yarn produced by the so-called ballooning method. In general, it can be stated that nanofibers are a promising element for current materials engineering. "They are used, for example, in the development of protective materials, sensors, cosmetics, hygiene products, tissue culture media, filters and energy storage materials [2].

Currently, the widest use for multistage electrodes is the production of yarns. The production of yarn, which consists of nanofibers, is a relatively important option in the field of spinning. Nanofiber yarns can be the basis for the production of fabrics or knitwear. These fabrics made from nanofiber yarns can be used to make high value-added products such as protective clothing, high performance fabrics and composites, or they can be used in areas such as tissue engineering. Increasing the technological level of nanofiber yarn production requires finding a way to transform polymer nozzles into linear nanofiber assemblies and achieve a satisfactory level of process productivity [3].

This study aims to create a nanofiber structure with a majority of fibers of two different finenesses. A particular two-stage electrode (Figure 1) should be used for this, consisting of two different electrodes placed one above the other. Each stage of this so-called multistage electrode has a different value of the electrical field, so it is assumed that there is a probability to produce fibers with varying fineness at each stage. 


\section{ANALYSIS OF A SPECIAL TWO-STAGE ELECTRODE}

Simulation Multiphysics software was used to determine the electrical field on the particular two-stage electrode. This simulation software provides precise and flexible tools for calculating boundary value problems using the finite element method (FEM). The assembled mathematical model allows simulating the charge distribution in an electrical field.

Due to the experimental device's axial symmetry, the mathematical model can be solved as a two-dimensional problem with axial symmetry. The FEM model's $2 \mathrm{D}$ geometry was created by the experimental equipment dimensions described in the experiment (Chapter 3). The material properties of the individual parts of the device were defined in the model using relative permittivity. The critical states of the electrospinning process were described in a mathematical model by the applied voltage. A grounded protective box was defined as a sphere with an outer diameter of $2000 \mathrm{~mm}$ and an applied voltage of $0 \mathrm{~V}$ at its outer boundary [4]. The boundary condition for the spinning electrode was $30 \mathrm{kV}$, the same value was subsequently used in the experiment.

The type of analysis "Electrical field and voltage" was chosen for the simulation. The electrical field distribution in the model is shown in Figures $\mathbf{1} \mathbf{a}, \mathbf{b}, \mathbf{c}$. The results of the analysis shown in the figures correspond to the cases in the assembly 3, 4 and 5 in the Table 1 . The assembly 5 shows the considerable difference in electrical field value between the first and second electrode stages, which is in the case shown in Figure 1 a).
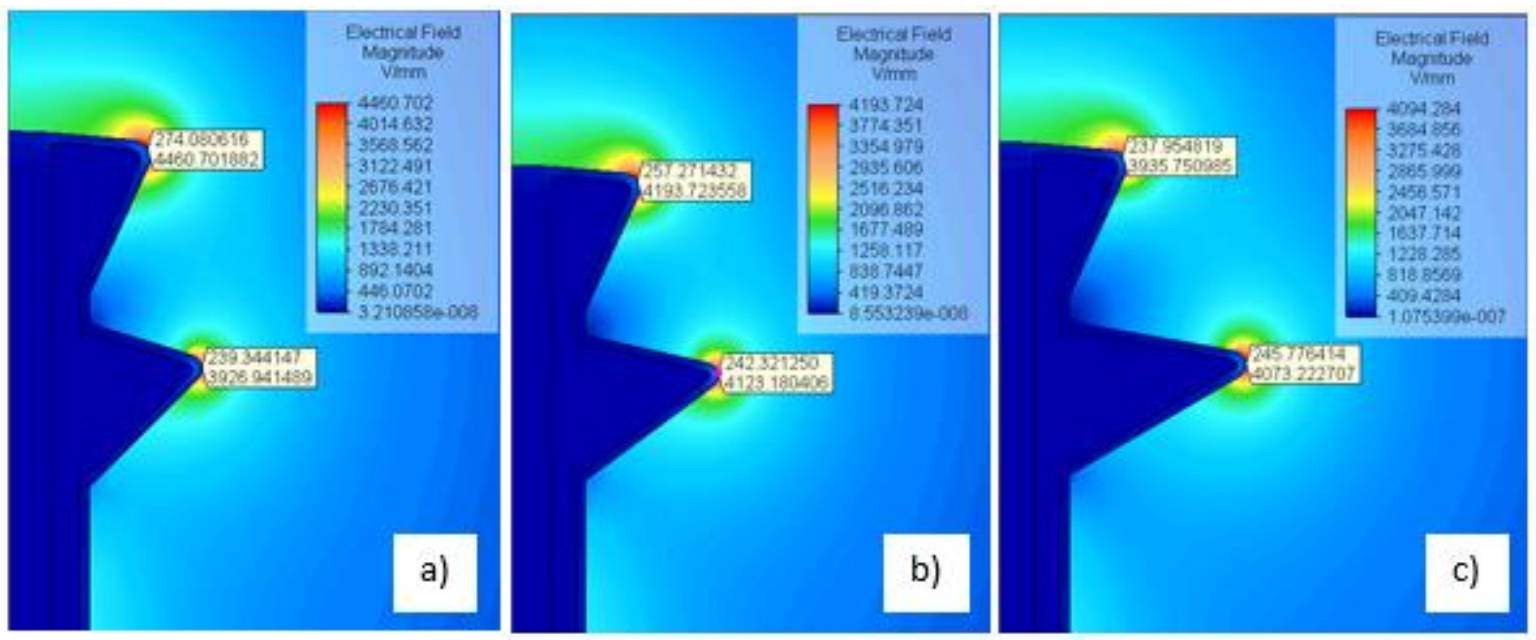

Figure 1 Electrical field distribution

\section{EXPERIMENT}

For the experiment, a group of special elements was designed and manufactured, from which it is possible to assemble a two-stage electrode [5]. Thanks to the interchangeability of parts, the parameters of individual electrode stages can be changed. The two-stage electrode has an axially symmetrical geometry and consists of support and a working part. The supporting part consists of a steel tube with an outer diameter of $8 \mathrm{~mm}$ and a height of $150 \mathrm{~mm}$. The working part consists of interchangeable cone-shaped steel electrodes- stages. These stages are placed on top of each other on the support part to form the so-called "tree shape".

During the experiment, the two-stage electrode was assembled so that 1 stage was formed by an electrode with a diameter of $15 \mathrm{~mm}$ with a functional radius of $0.5 \mathrm{~mm}$. The second stage was replaced by electrodes with diameters of 20,24 , and $28 \mathrm{~mm}$ with an operating radius of $0.3 \mathrm{~mm}$ on the outer perimeter. A voltage of $30 \mathrm{kV}$ was applied to the electrode. The experiment itself was performed in a grounded protective box.

Polyvinyl butyral (PVB, Mowital B6OH) was used for the experiment. The solution contained $9 \%(\mathrm{w} / \mathrm{w})$ of polymer, the remainder of the solvent. The solvent was stirred from ethanol and isopropyl alcohol in a ratio of 
4: 1 . The polymer was conveyed to the electrode through the center of the steel tube (support part) by means of a peristaltic pump. The experiment was done at an ambient temperature of $23^{\circ} \mathrm{C}$ and relative humidity of $40 \%[6]$.

In the experiment, five different sets of electrodes were measured. For each set, three samples of a planar fibrous structure were taken on a black base paper. The task was to compare three different assemblies of the tree electrode with three other differences in electrical field. It was assumed that the samples would show a different percentage of fibers of a certain fineness [7]. The electrical field distribution on the tree electrode and the maximum values of the electrical electrical on the individual stages of the electrode are described in detail in the analysis.

\subsection{Used electrode assemblies}

Table 1 Assemblies of used electrodes within the experiment

\begin{tabular}{|c|c|c|c|}
\hline Case & \multicolumn{2}{|c|}{ Figure } & Assemblies \\
\hline 1 & \multicolumn{2}{|c|}{2 a) } & The rod itself with a diameter of $8 \mathrm{~mm}$ - verification of operation \\
\hline 2 & \multicolumn{2}{|c|}{$2 \mathrm{~b})$} & Single-stage electrode - diameter $28 \mathrm{~mm}$ - verification of operation \\
\hline 3 & 1 a) & \multirow{3}{*}{$2 \mathrm{c})$} & Two-stage electrode - 1 st. diameter $15 \mathrm{~mm}, 2$ st. diameter $28 \mathrm{~mm}$ \\
\hline 4 & $1 \mathrm{~b})$ & & Two-stage electrode - 1 st. diameter $15 \mathrm{~mm}, 2$ st. diameter $24 \mathrm{~mm}$ \\
\hline 5 & 1c) & & Two-stage electrode - 1 st. diameter $15 \mathrm{~mm}, 2$ st. diameter $20 \mathrm{~mm}$ \\
\hline
\end{tabular}

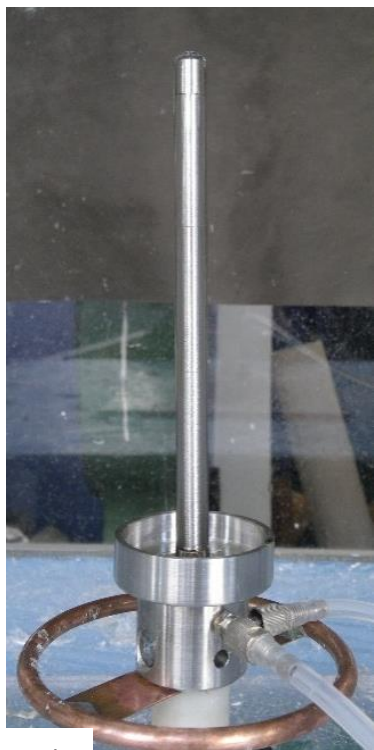

a)
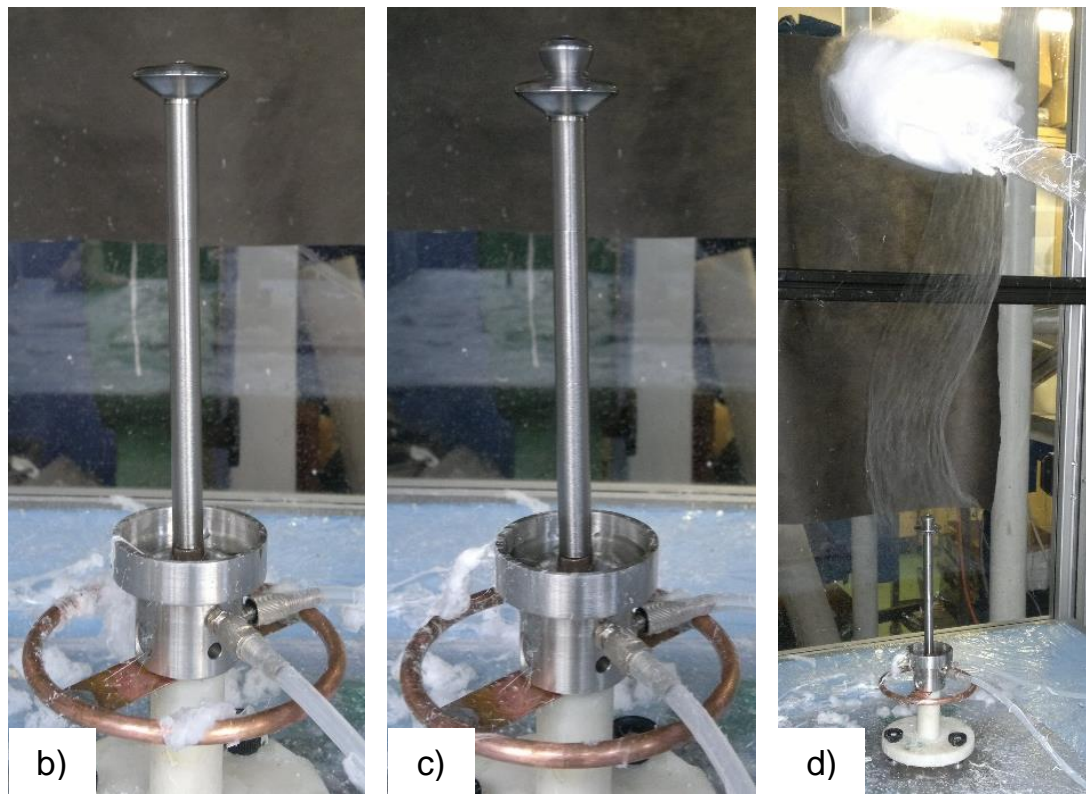

Figure 2 a) rod, b) single-stage electrode, c) two-stage electrode, d) spinning process

\section{EVALUATION}

Three samples were taken for each assembly and subsequently scanned with an electron microscope (Figure 3). 15 images were taken for each assembly. The obtained images were evaluated using software where fiber thicknesses were measured. One hundred values were measured on each image. The evaluated results are shown in Figures $\mathbf{3}$ to $\mathbf{5}$, the graphs in the mentioned figures present the quantity of fibers' representation of the certain fineness in the samples taken from assemblies (Table 1, case 3, 4 and 5). 

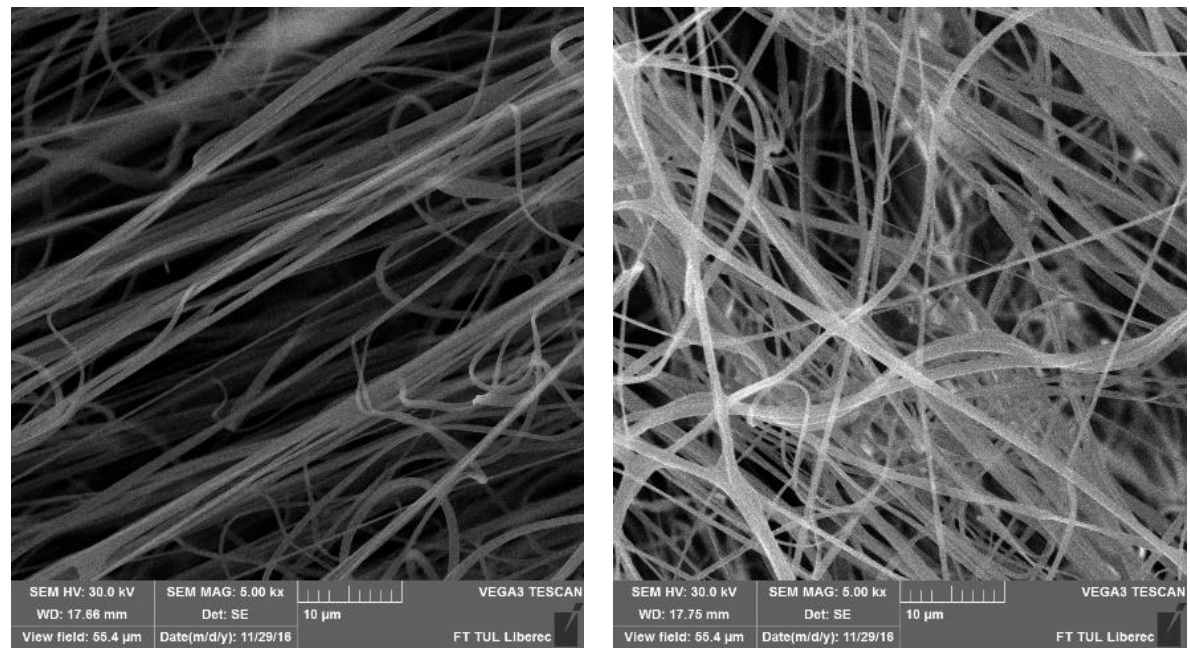

Figure 3 SEM images - assembly 3

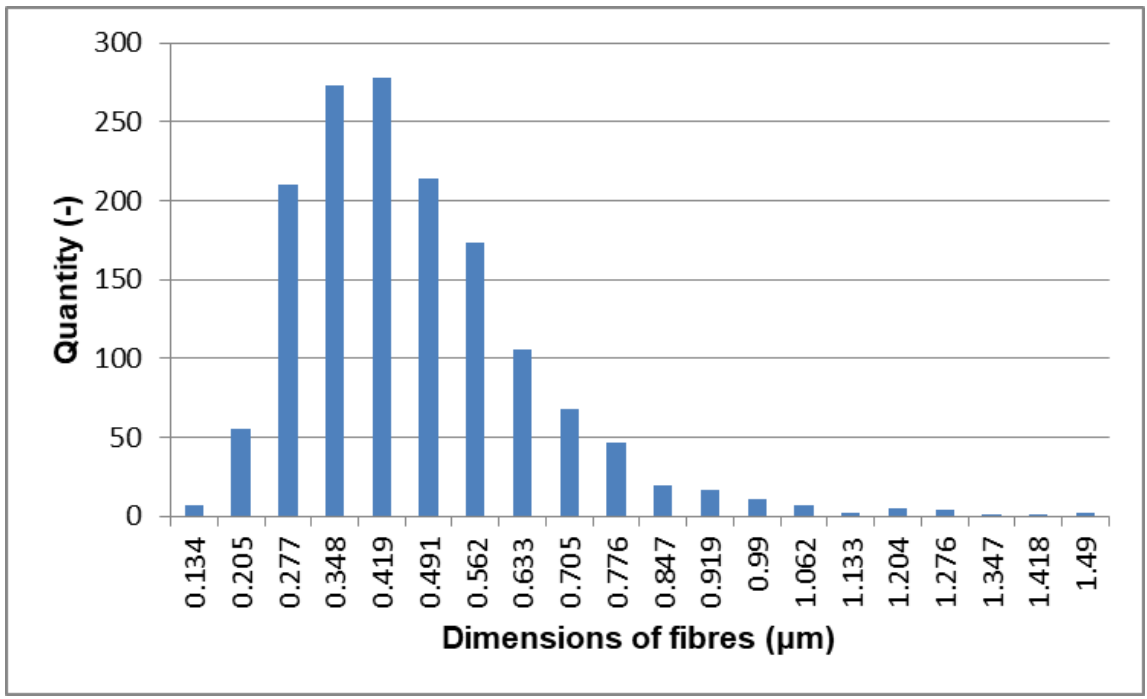

Figure 4 Distribution of fiber fineness - case 1 (Table 1)

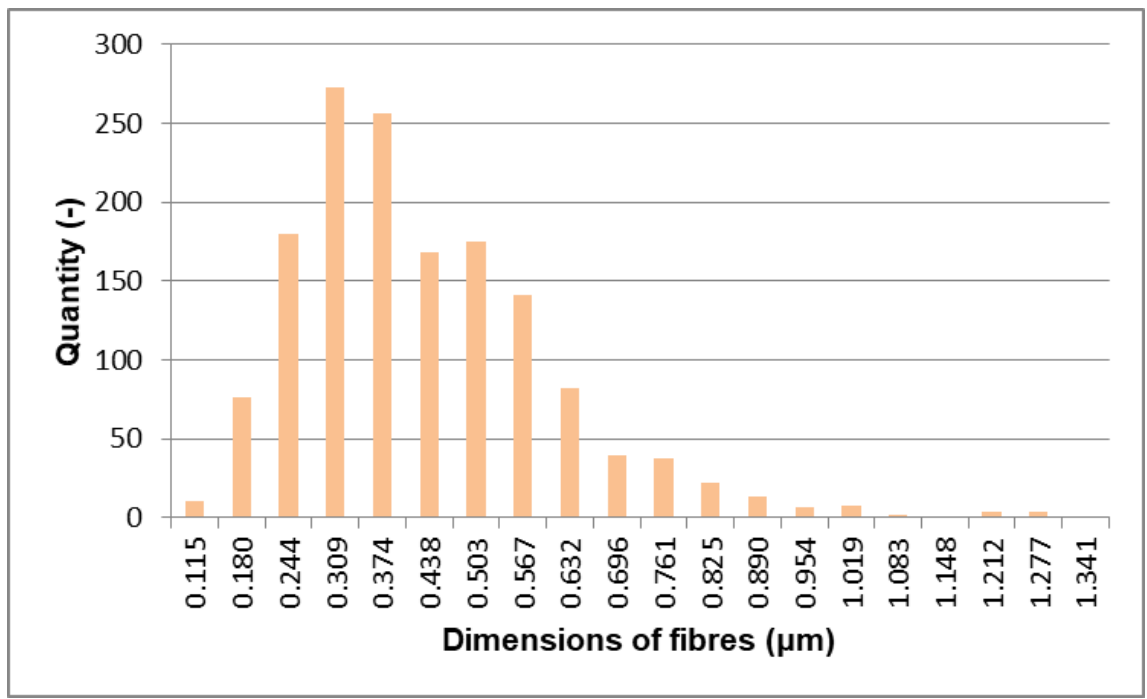

Figure 5 Distribution of fiber fineness - case 2 (Table 1) 

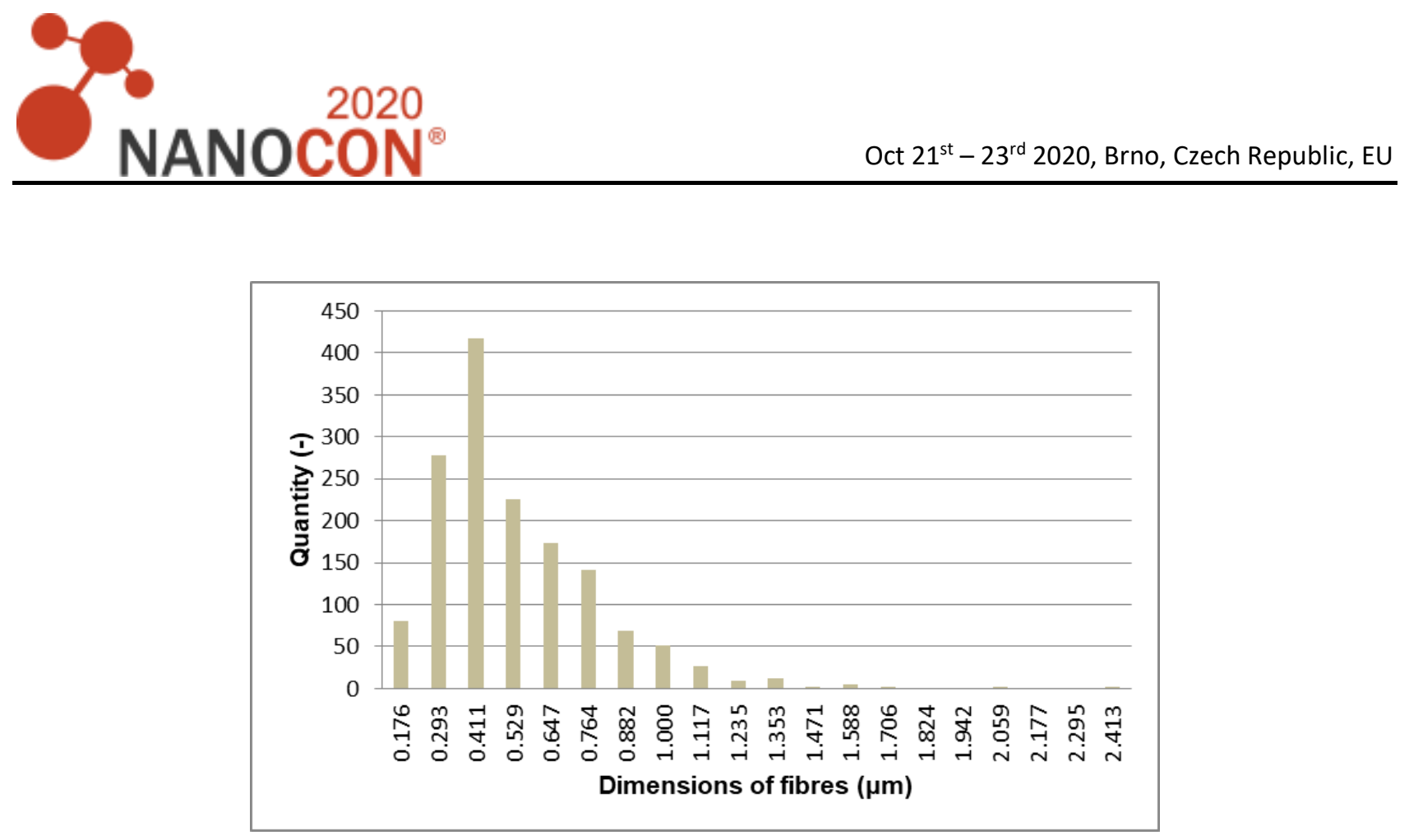

Figure 6 Distribution of fiber fineness - case 5 (Table 1)

\section{CONCLUSION}

The two-stage electrode in case 5 (Table1, Figure 1a) has a lowest difference in electrode diameters on the first and second stages. The diameter of the first stage is $15 \mathrm{~mm}$ and the second one is $20 \mathrm{~mm}$ (Figure 1a). On the other hand, the difference between the maximum values of electrical field at the individual stages is the largest for this assembly, yet this difference is $12 \%$. The evaluated samples have the largest proportion of fibers with a fineness $0.411 \mu \mathrm{m}$ (Figure 6).

A large proportion of fibers with two different finenesses is not significantly apparent from the sample. The cause may be a small difference in the maximum electrical field at the individual electrode stages. This fact could also be influenced by the different production of fibers at each stage of the electrode. The quantity of fibers from the second stage of electrode would be in such a small amount that it would not significantly stand out from the other values of fineness in the represented results. Productivity is related to an electrical field so that the higher the intensity value, the higher the productivity [3]. From the small difference in the electrical field between the individual stages of the electrode, the previous consideration could be ruled out. Productivity could also be affected by shading one electrode by another. From the analysis results shown in Figure 1 also implies that with increasing diameter of the lower stage of the electrode there is a decrease of the electrical field at the upper stage of the electrode.

It is also worth mentioning the evaluated samples of assemblies case 1 and case 2 (Table 1), although it is not a tree electrode. The results can be compared in Figures $\mathbf{4}$ and $\mathbf{5}$. The values of the fineness of the most represented fibers differ slightly here. Thus, there is some hope that the idea of creating a nanofiber structure with a large proportion of fibers of different fineness is not wrong. It would be interesting to further deal with this task and design a two-stage electrode with an enormous difference in electric field between the individual stages for further tests.

\section{ACKNOWLEDGEMENTS}

This publication was written at the Technical University of Liberec as part of the project with the support of the Specific University Research Grant, as provided by the Ministry of Education, Youth and Sports of the Czech Republic in the year 2020. 


\section{REFERENCES}

[1] TECHNICAL UNIVERSITY OF LIBEREC. Method of nanofibers production from polymeric solution using electrical spinning and device for carrying out the method. JIRSAK, O. Czech Republic, 2015. WO2005024101.

[2] LUKAS, D. Physical principles of Electrospinning. Journal of Applied Physics. 2008, ISSN (E-ISSN) 1089-7550.

[3] VAlTERA, J., KALOUS, T., POKORNY, P., BATKA, O., BILEK, M., CHVOJKA, J, LUKAS, D. Fabrication of dualfunctional composite yarns with a nanofibrous envelope using high throughput $A C$ needleless and collectorless electrospinning. Scientific Reports. [online]. 2019, vol. 9, article no. 1801. Available from: https://doi.org/10.1038/s41598-019-38557-z.

[4] KOMAREK, J., VALTERA, J., SOUKUPOVA, J., VYSLOUZILOVA, L., SKRIVANEK, J., ZABKA, P., BERAN, J., LUKAS, D. Verification of the mathematical model of the rod electrode in the electrospinning process. In: Nanocon 2015: $7^{\text {th }}$ International Conference on Nanomaterials. Ostrava: TANGER, 2015.

[5] TECHNICAL UNIVERSITY OF LIBEREC. Method for producing polymeric nanofibres by electrospinnig a polymer solution or melt, a spinning elektrode for performing the metod and a device for producing polymeric nanofibers equipment with at least one cush spinning electrode. BERAN, J., VALTERA, J., BÍLEK, M., SKŘIVÁNEK, J., KOŠŤÁKOVÁ, E. Czech Republic, 2017. EP 3394328.

[6] MACDIARMID, A.G., JONES, W.E., NORRIS, I.D., GAO, J., JOHNSON, A.T. JR., PINTO, N.J., HONE, J., HAN, B., OKUZAKI, H., LLAGUNO, M. Electricalally-generated nanofibers of electronic polymers. Synthetic Metals. Pennsylvania: University of Pennsylvania, 2001, p. 27.

[7] JIN, H.-J., FRIDRIKH, S.V., RUTLEDGE, G.C., KAPLAN, D.L. Electrospinning Bombyx mori Silk with (Polyethylene oxide). Biomacromolecules. American Chemical Society, 2002, p.408. 